\title{
TRABALHADORES RURAIS E MIGRAÇÃO NA CALIFÓRNIA DOS ANOS 30: JOHN STEINBECK E OS "CIGANOS DA COLHEITA"
}

\author{
RURAL WORKERS AND MIGRATION IN 1930S CALIFORNIA: JOHN \\ STEINBECK AND THE "HARVEST GYPSIES"
}

\author{
Lucas André Berno Kölln ${ }^{1}$
}

\begin{abstract}
RESUMO: No verão de 1936, o romancista John Steinbeck viajou a soldo do jornal The San Francisco News para cobrir o fenômeno dos migrantes que se apinhavam pelas estradas da Califórnia e dos Estados Unidos no rescaldo dos dust bowls e da crise de 1929. Como resultado da viagem, Steinbeck escreveu sete artigos que foram publicados em outubro de 1936 e batizados de "Os ciganos da colheita". Esses textos têm grande valor documental sobre os efeitos sociais da recessão econômica e, esse é nosso argumento, participaram de maneira fundamental da mudança de perspectiva da literatura de Steinbeck, tornando-a mais politicamente engajada e esteticamente realista. O propósito desse artigo é entender como a experiência do verão de 1936 alterou a percepção crítica de Steinbeck acerca da realidade estadunidense, entendendo que os migrantes foram fundamentais nesse processo, visto que explicitaram o parentesco histórico entre os trabalhadores e as antigas classes médias rurais às quais o escritor pertencia. Essa descoberta realçou o clamor democrático de sua literatura, o qual culminou no maior romance sobre a Grande Depressão: As vinhas da ira de 1939.
\end{abstract}

PALAVRAS-CHAVE: Grande Depressão; História dos Estados Unidos; John Steinbeck

ABSTRACT: In the summer of 1936, the novelist John Steinbeck was hired by the newspaper The San Francisco News to cover the phenomenon of the migrants that crowded the roadsides of California and the United States in the aftermath of the dust bowls and the 1929 crisis. As a result of the field trip, Steinbeck wrote seven articles that were published in October 1936 and called "The harvest gypsies". These texts have great documental value regarding the social effects of the economic recession and, this is our argument, they play a fundamental role in the change of perspective in Steinbeck's literature, making it more politically engaged and aesthetically realistic. This article aims at

\footnotetext{
${ }^{1}$ Doutor em História pela Universidade de São Paulo e professor do Colegiado de História da Universidade Estadual do Oeste do Paraná (Unioeste). Email: lucas_kolln@ @otmail.com
} 
understanding how the summer of 1936 altered Steinbeck's critical perception over the American reality, underscoring the fact that migrants were pivotal in such process, since they uncovered the historical kinship between the workers and the old rural middle classes to which the writer belonged. This discovery enhanced the democratic claims of his literature, which peaked in the greatest novel about the Great Depression: 1939's The grapes of wrath.

KEYWORDS: Great Depression; United States History; John Steinbeck.

Esse artigo busca analisar alguns dos mais importantes textos jornalísticos produzidos por Steinbeck: a série que mais tarde ficou conhecida como The harvest gypsies (Os ciganos da colheita), originalmente escritos e publicados em 1936, no jornal The San Francisco News. Neles, Steinbeck analisa o grande processo migratório que tomou os Estados Unidos nos anos que se seguiram à crise econômica de 1929, provocado também pelas terríveis tempestades de areia (dust bowls) que assolaram o sul do país entre 1935-1938, especialmente na porção meridional das Grandes Planícies.

Há hoje razoável consenso de que essa calamidade resultou de uma combinação de vários fatores, que vão desde o uso intensivo da terra na escalada econômica iniciada na Primeira Guerra, até a Grande Seca de 1934, passando pela queda dos preços agrícolas e pela inadimplência hipotecária dos pequenos proprietários, ambas tendo concorrido para deixar grandes extensões de terra sem cultivo. Esse conjunto de elementos potencializou os endêmicos ventos da região, tornando-os destrutivos de modo inédito. A superfície do solo era arrancada pelo vento, e como a seca e a ausência de cultivo deixavam-no sem aderência, formavam-se verdadeiras muralhas de poeira que engoliam o que estivesse em seu caminho. As fotografias produzidas na época imortalizaram o retrato da catástrofe, espécie de desertificação geral: carros com rodas atoladas na poeira, casas tão submersas no pó que somente se via seu telhado, nuvens de terra muitas vezes mais altas que as casas e os celeiros das pequenas propriedades.

O desastre natural e humano chamou a atenção nacional, atingindo em cheio o espírito estadunidense, já combalido pela crise de 1929. O jornalista Ernie Pyle, da fronteira do Oklahoma em junho de 1936, escreveu: "Se você 
quiser ter seu coração despedaçado, basta vir até aqui. (...) É o lugar mais triste que já vi." (apud DUNCAN; BURNS, 2012: p. 158) Para completar o quadro desolador, desfilavam nas estradas hordas de migrantes empoeirados, fugindo tanto da catástrofe natural quanto do desemprego e das dívidas. A combinação terrível de aridez econômica e ambiental parecia seguir a lógica que Galbraith disse ser uma particularidade da crise de então: "O aspecto singular do grande craque de 1929 era que o pior continuava a piorar. O que parecia um dia ser o fim provava no dia seguinte ser apenas o começo." (GALBRAITH, 1972: p. 147)

Despencando nesses patamares de piora estava o enorme contingente de migrantes, protagonistas inglórios daquele grande movimento que Dorothea Lange e seu marido Paul Taylor chamaram de "êxodo americano" (LANGE; TAYLOR, 1969). Os números de migrantes que se dirigiram à Califórnia nos anos 1930 é estimado entre 350 e 400 mil, adidos de mais 600 a 700 mil durante a Segunda Guerra (GREGORY, 1989: p. 76), e vinham de estados mais próximos e mais distantes: Arkansas, Novo México, Oklahoma, Texas, Missouri, Arizona, Nebraska, Kansas. ${ }^{2}$

Arrastando-se com seus pertences pelas estradas, essa precária procissão tornou-se o símbolo das incertezas americanas.

Órgãos federais foram rapidamente criados, aumentados ou redirecionados para lidar com esses efeitos devastadores, redimensionando o programa de recuperação e reformas empreendido por Roosevelt, o New Deal. O Natural Resources Conservation Service (NRCS), criado em setembro de 1933, foi encarregado de descobrir a causa das tempestades e de oferecer uma solução de manejo ecológico para evitar episódios semelhantes. O Federal Surplus Commodities Corporation (FSCC), criado em outubro de 1933, teve parte de suas funções de aquisição de excedente produtivo dirigidas para as

\footnotetext{
${ }^{2}$ Para que se possa dimensionar concretamente a magnitude dessa jornada, cabe mencionar a distância delas em relação à parte central da Califórnia, tomando Fresno como referência, já que ele fica próximo do Vale San Joaquin, destino de muitos desses migrantes. A distância entre este ponto e os estados de Arkansas, Texas, Nebraska, Kansas e Missouri (a depender dos exatos ponto de partida e destino e da exata rota adotada) gira em torno de $2500 \mathrm{~km}$, em relação a Oklahoma facilmente ultrapassa 2000km, de Novo México se aproxima de $1400 \mathrm{~km}$, e mesmo do estado vizinho do Arizona pode ser superior a 1000km.
} 
regiões rurais atingidas. O Drought Relief Service (DRS), de 1935, passou a comprar o gado sobrevivente das fazendas afetadas, por vezes distribuindo a carne através de programas de assistência social como os das famosas "filas de pão". E o principal desses órgãos, o Farm Security Administration (FSA), que entre 1935-1937 teve o nome de Resettlement Administration, ${ }^{3}$ gerenciou extensivamente o reassentamento das famílias e a reorganização da produção agrícola.

A Farm Security Administration interessa-nos aqui também porque, como braço agrário do New Deal, atuou no sentido de documentar o fenômeno dos dust bowls e da Grande Depressão. Muitas das fotografias clássicas produzidas durante esse período foram diretamente financiadas por agências governamentais ou então indiretamente estimuladas por tais esforços. Fotógrafos como Dorothea Lange, Arthur Rothstein, Russell Lee, Walker Evans e outros tantos ${ }^{4}$ acabaram tendo seu nome permanentemente associado à obra que produziram sob esses auspícios.

Embora John Steinbeck não tenha trabalhado a soldo do governo nessa época, seu trabalho pelo The San Francisco News se assemelha muito ao espírito dos artistas e jornalistas recrutadas pela FSA e outros órgãos do governo Roosevelt - os new dealers, como ficaram conhecidos. Assim como aqueles, Steinbeck tinha um envolvimento muito direto com a matéria de sua arte, primava pelo realismo (por vezes quase documental), e buscava colocar a moldura do trágico sobre os migrantes sem se deixar prostrar pelo pessimismo absoluto, por vezes inserindo algum otimismo patriótico nas entrelinhas.

O argumento que sustentamos é de que a série "Os ciganos da colheita" permitiu que Steinbeck constatasse o parentesco histórico entre as antigas classes médias rurais e a classe trabalhadora, tendo sido a migração de então o catalisador dessa epifania. O que estes expressavam na sua heterogeneidade de origem e de trato era o processo de proletarização resultante da crise

\footnotetext{
${ }^{3}$ Entre 1942-1945, o FSA foi vinculado ao Office of War Information (OWI).

${ }^{4}$ A Biblioteca do Congresso dos Estados Unidos (United States Library of Congress) possui pródigo acervo desse material, contando com mais de 175 mil negativos em preto-e-branco acerca dessa época. Disponível em: https://www.loc.gov/pictures/collection/fsa/ Acesso em: 20 mar. 2020.
} 
econômica, concomitantemente à concentração oligopólica, ambas a diluir as antigas fronteiras socioeconômicas e nivelar todos por baixo.

Para melhor organizar a argumentação, dividimos o texto em dois momentos principais. No primeiro, se busca analisar a trajetória de Steinbeck como jornalista e passar em breve revista os textos que produziu nessa capacidade antes e depois dos anos 1930, ressaltando neles algumas características recorrentes, sobretudo seu realismo substantivo e suas ressonâncias patrióticas. No segundo, se analisa criticamente a obra de Steinbeck nos anos 30 para perceber como a experiência de 1936 junto dos migrantes constitui ponto de viragem de sua literatura, assim ressaltando seu significado tanto particular quanto social e histórico.

\section{O jornalismo de Steinbeck e o lugar dos artigos de 1936}

John Steinbeck é conhecido por ser um dos grandes escritores estadunidenses, o romancista da Grande Depressão por excelência, e sobretudo por ser o autor de As vinhas da ira (The grapes of wrath), indiscutivelmente um dos "Great American Novels". Ao longo de sua gênese como escritor, no entanto, um outro ofício correu ao lado de sua paixão pelas letras, um que, de forma intermitente, Steinbeck praticou antes e durante sua consagração como escritor: o jornalismo.

Numa entrevista a Jay Parini em 1993, o romancista norte-americano Gore Vidal chegou a dizer: "A verdade é que, no fundo de seu coração, Steinbeck era um jornalista. Seus melhores trabalhos eram jornalismo, no sentido em que eram inspirados por eventos cotidianos, por circunstâncias correntes." Arrematou dizendo que Steinbeck "(...) não inventava coisas. Ele as encontrava." (apud WHITT, 2006: p. 41) E mesmo o crítico Edmund Wilson, que tem uma visão pouco favorável à literatura de Steinbeck, concorda que é "detrás de seu jornalismo (...) permanece uma mente de primeira linha no seu imperturbável escrutínio da vida." (WILSON, 1951: p. 45) 
Em 1919, com 17 anos, Steinbeck deixou a pequena propriedade dos pais no Vale de Salinas, na península de Monterey, para ingressar na Universidade de Stanford, em Palo Alto. Entre as opções de graduação que indicou encontrava-se primeiro "Jornalismo", seguido de "Direito" e "Escrita criativa", sendo que a ênfase de sua formação seria definida de acordo com as disciplinas em que ele se matriculasse. Aquela primeira indicação era fruto de um cálculo profissional realista; a segunda provavelmente uma concessão à mãe; a terceira sua declarada paixão desde antes de 1919.

No colégio Steinbeck não fora um aluno exemplar, e assim permaneceu na universidade. Conhecido por ser inconstante e teimoso, Steinbeck não se adequou bem às exigências da vida acadêmica. (BENSON, 1984: pp. 32-36) Não tinha paciência para seguir as disciplinas, facilmente trocava as leituras obrigatórias pela literatura de sua predileção, e dedicava mais tempo e disciplina escrevendo contos no dormitório do que estudando nas salas de aula. Teve também sua dose de boêmia nesse tempo, indo a bares e cabarés em San Francisco, embora seus amigos tenham dito que sua educação protestante lhe refreava nesse sentido. Nesses termos frequentou Stanford entre 1920-1921, tendo sido formalmente advertido mais de uma vez quanto ao prognóstico que lhe aguardava caso continuasse avesso a seus deveres acadêmicos. Como seu comportamento não mudava, ao final do ano letivo de 1921 saiu a confirmação oficial: Steinbeck fora dispensado da universidade. (PARINI, 1998: p. 53)

Steinbeck demorou a voltar para casa após a dispensa, temendo a repercussão da notícia junto de sua mãe, protestante rigorosa. Não tendo conseguido se estabelecer de outro modo noutro lugar, no entanto, e decepcionado por ter de admiti-lo, acabou por voltar à casa dos pais no final de 1921. Por quase dois anos Steinbeck viveu ali, ora estabelecendo-se nalgum emprego mais tradicional, ora movimentando-se pelos arredores do vale de Salinas junto com peões e trabalhadores rurais envolvidos com trabalho manual. O projeto de virar escritor continuava vivo, mas foi submetido a um teste de realidade que o deixou mais pragmático, pois Steinbeck experimentou 
as dificuldades que esperavam trabalhadores sem profissionalização e sem um diploma. (BENSON, 1984: p. 58)

Isto provavelmente contribuiu para que ele tomasse a decisão de retomar o estudo universitário. Voltou a Palo Alto no inverno de 1923 e tentou enraizarse ali até 1925, período em que aparentemente teve mais sucesso do que no anterior, mas não o suficiente: na iminência de uma nova reprovação e dispensa, Steinbeck decidiu abandonar definitivamente a formação acadêmica no final desse ano. Ou seja, apesar de ter cursado disciplinas voltadas à escrita $\mathrm{e}$ ao jornalismo, a despeito de ter participado de debates literários e políticos na universidade, o período de 1919-1925 terminou sem que ele conquistasse diploma algum.

Conforme seu biógrafo Jackson Benson (1984: pp. 70-72), em parte por necessidade, em parte por opção, Steinbeck dedicou muito maior energia perambulando pela Califórnia nesses anos, atrás de trabalhos provisórios, de aventuras juvenis e de histórias - de migrantes, peões, vagabundos e toda um conjunto de gente comum. Essas experiências temperaram seu espírito e sua escrita, concorrendo para formar aquela dicção substantiva e séria que lhe é característica, compartilhada por ambos seu jornalismo e sua literatura.

$\mathrm{Na}$ década de 1920, a despeito de sua não-certificação oficial como jornalista, Steinbeck chegou a trabalhar como um. (FRENCH, 1966: p. 19) Por alguns meses esteve vinculado ao periódico The American, em Nova York, por arranjo de um parente seu de Chicago. Como novato, ficou encarregado de cobrir eventos triviais como aqueles que costumam compor notas rápidas de jornal, efemérides mesmo, tais como o "Day of Courtesy", quando o prefeito de Nova York oficializou uma campanha em nome das boas maneiras, que julgava perdidas na cidade. Histórias insossas como esta, no entanto, acabavam levando Steinbeck para lugares como o Brooklyn ou o Queens, nos quais ele se perdia por horas observando habitantes e costumes locais. Os contos que ele enviava para revistas e jornais nessa época, buscando ganhar algum dinheiro, demonstram como ele treinava seus olhos e usava essa matéria-prima humana para além do mero interesse jornalístico: um deles falava de um ex-lutador de 
boxe que trabalhava como funcionário de uma corretora imobiliária, que ele testemunhara; outra era uma história de Natal que se passava na $3^{\text {rd }}$ Street, por onde ele circulava; e havia o conto sobre Elsie Grough, uma garota desmiolada e atraente que "costuma ficar esperando nas entradas do metrô" - o conto se intitulava "A irmã branca da Rua Quatorze", outro endereço nova-iorquino. (BENSON, 1984: p. 97)

Esse aprendizado, marcado pela formação irregular, pelo gosto pela observação em primeira mão e pela dicção terra-a-terra definiram um leito nãoficcional sólido na escrita de Steinbeck, sobre o qual a ficção pôde ser canalizada até eventualmente transbordá-lo de modo autônomo. Por conta disto, nos anos 1930 e nas décadas seguintes, Steinbeck escreveu muitos textos jornalísticos, ou, se preferirmos, textos não-ficcionais que foram publicados em jornais e revistas, nos quais prevalece linguagem claramente jornalística, seja mais próxima da reportagem, seja mais aparentada à crônica.

Pode-se colocar sob esse cabeçalho um texto como o roteiro de The forgotten vilage (A vila esquecida, em tradução livre), de 1941, documentário dirigido por Herbert Kline nesse mesmo ano. Nele o aspecto informativo e didático é típico de certa variedade de jornalismo, o que o torna conscienciosa reportagem semi-dramatizada sobre a desolação numa vila mexicana abandonada pelo governo. A atenção ao detalhe factual e a contenção material e figurativa do texto também indicam a cepa jornalística apesar do propósito cinematográfico.

$\mathrm{Na}$ categoria de livro-reportagem encontra-se outra obra de Steinbeck dos anos 1940, Um diário russo (A Russian journal), de 1948, fruto de uma corajosa viagem do escritor e do fotógrafo Robert Capa à União Soviética em 1947, nas priscas eras da Guerra Fria. Apesar da moldura de diário, muito da abordagem analítica e do rigor informativo do texto conferem estatuto jornalístico ao livro, permitindo que leitores "ocidentais" constatassem que os soviéticos não eram assim tão diferentes deles quanto dizia a inflamada propaganda ideológica da época. É bastante provável que esse esforço tenha concorrido para que o nome de Steinbeck figurasse nos relatórios do Comitê de 
Atividades Anti-Americanas nos anos 1940-1950 (MITGANG, 1987) - embora persista ainda hoje a controvérsia quanto a onde situar o escritor nesse sentido. ${ }^{5}$

Encontram-se também sob a rubrica de textos jornalísticos (nesse caso com maior rigor no uso do qualificativo) a considerável produção de Steinbeck sobre as guerras em que os Estados Unidos participaram no século XX.

O polêmico Bombs away: The story of a bomber team (Soltar bombas! A história de um esquadrão bombardeiro, em tradução livre), de 1942, foi o produto de uma solicitação da Força Aérea Americana, que o comissionou a escrever reportagens sobre sua experiência com os bombardeiros durante a Segunda Guerra Mundial, desde a produção deles em solo norte-americano até sua operação destrutiva no teatro de guerra europeu. As reportagens de Once there was a war (Era uma vez uma guerra, em tradução livre), feitas à soldo do jornal The New York Herald Tribune em 1943 e reunidas em edição de 1958, seguem padrão similar, com a diferença de serem menos propagandísticas e terem mais o aspecto de um diário de campo. E mesmo já coroado com as louros do Nobel de Literatura, Steinbeck viajou ao sudeste asiático entre 19661967, dessa vez como correspondente de guerra do jornal Newsday, tendo produzido textos que só recentemente foram reunidos em forma de livro, em 2012, na coletânea Steinbeck in Vietnam - Dispatches from the war (Steinbeck no Vietnã - Despachos da guerra, em tradução livre).

Como parte de um "esforço de guerra" (ora oficial, ora diletante) de Steinbeck, todos esses livros deixam entrever o teimoso patriotismo "casca grossa" das antigas classes médias dos Estados Unidos. Aquele mesmo que no escritor parece ser a um tempo seus cabelos de Sansão e seu calcanhar de Aquiles: fonte de uma força humanista arrebatadora quase todo o tempo, mas eventualmente padecendo de uma ingenuidade restritiva e comprometedora.

\footnotetext{
${ }^{5}$ Em 2013, o cientista político Brian Kannard publicou o livro Steinbeck: Citizen spy - The untold history of John Steinbeck and the CIA (Steinbeck: cidadão espião - A história nãocontada de John Steinbeck e a CIA, em tradução livre), no qual analisa documentos da Agência e pelo FBI tornados públicos recentemente, dentre os quais se destaca uma carta de 1952 ao diretor da CIA Walter Bedell Smith, na qual o escritor se oferece para trabalhar como informante durante uma viagem que faria a Europa.
} 
Outros textos jornalísticos de Steinbeck se afinam a essa verve patriótica. Praticamente todos os escritos reunidos na coletânea A América e os Americanos (America and the Americans), de 1966, têm esse ponto em comum; e essa também é a nota que se sobressai nos escritos de sua peregrinação pelos Estados Unidos com seu cachorro em 1960, publicados em forma de livro com o título Viajando com Charley (Travels with Charley) em 1962, cujo subtítulo é "Em busca da América" (In search of America). Há em ambos algo como uma etnologia folclórica mesclada com crítica social, que ora desvia para a crônica, ora encarna o escrito memorialístico. Em quase todos os textos prevalece aquele esforço tipicamente jornalístico de Steinbeck: descrições de materialidade farta, buscando divisar contornos explicativos amplos e estabelecer o lugar das pequenas coisas neles, sem deixar de localizar-se o autor diante desse todo.

Os textos da série "Os ciganos da colheita" constituem parte dessa trajetória: à meia-distância entre os primórdios do jornalismo errático dos anos 1920 e sua participação como jornalista no "esforço de guerra" dos anos 1940. Diante da produção jornalística dos anos 50 e 60, construída já com a estatura de uma autoridade nacional, os artigos de 1936 parecem um grito de juventude contra a injustiça, encravado no coração daquela década paradoxalmente árida e fecunda. Se esse passeio pelo lado selvagem pode ser lido pelos mais conservadores como uma justificada reação ao saldo humano da Grande Depressão, não deixa também de mostrar também o quão radical pode eventualmente ser o patriotismo americano.

Os sete artigos em questão foram publicados entre 5 e 12 de outubro de 1936 no The San Francisco News, e tamanha comoção causaram que em maio de 1938 foram cedidos pelo escritor a Simon J. Lubin Society of California, organização de apoio aos migrantes despossuídos, para serem publicados em forma de panfleto, sob o título Their blood is strong (O sangue deles é forte, em tradução livre). O panfleto trazia na capa uma fotografia de Dorothea Lange, além de outras vinte e duas em seu interior. Especialmente para essa publicação, Steinbeck escreveu um oitavo artigo, intitulado "Starvation under 
the orange trees" ("Fome sob as laranjeiras", ${ }^{6}$ em português), provavelmente seu último texto antes de mergulhar na escrita do monumental As vinhas da ira.

Em 1988 a editora californiana Heyday Books publicou uma coletânea com os sete artigos originais sob o título The harvest gypsies (STEINBECK, 1988), que continha o seguinte subtítulo: "À caminho d'As vinhas da ira". Se se desenterrar as raízes históricas desse romance e cruzá-las com a trajetória biográfica e bibliográfica de Steinbeck, é possível fazer a engenharia reversa de sua ficção e traçar uma evolução processual, orgânica, de 1936 a 1939. Mais precisamente: do início de 1936 (quando Steinbeck foi contratado pelo The San Francisco News, segundo Charles Wollenberg [In: STEINBECK, 1988: p. v]) até os cinco meses de junho a outubro de 1938 (quando Steinbeck escreveu As vinhas da ira, segundo Robert DeMott [In: STEINBECK; DeMOTT, 1990: p. xxi]).

No início de 1936, sob os auspícios de um tão adequado anfitrião como o muckraker Lincoln Steffens, Steinbeck recebeu o convite de George West, editor do The San Francisco News, para empreender uma viagem ao sul da Califórnia e escrever alguns artigos sobre a situação dos trabalhadores rurais e migrantes na beira das estradas e nos acampamentos federais e estaduais recémfundados. Estabelecido o acordo, em pouco tempo Steinbeck estava a bordo de um furgão outrora pertencente a uma padaria, mais tarde batizado de "pie wagon" (furgão de tortas), seguindo o rastro dos despossuídos.

O órgão federal responsável pela manutenção e gerência dos acampamentos da região era o Resettlement Administration (ou Farm Security Administration, a partir de 1937). Quem os administrava era Tom Collins, a segunda pessoa a quem Steinbeck dedicou As vinhas da ira. Os biógrafos de Steinbeck concordam que a agência federal buscava boa publicidade e viu naquele jornalista uma ótima oportunidade de alcançá-la. Da parte de Steinbeck, o auxílio de Collins foi muito bem vindo, pois este tornou-se seu Virgílio no dantesco universo que ousava adentrar: ele conhecia as beiras de rio

\footnotetext{
${ }^{6}$ Esse texto foi incorporado na coletânea de artigos de 1966, America and the Americans, e pode ser encontrado na edição brasileira (Record, 2004) com tradução de Maria Beatriz Medina, entre as páginas 111-116.
} 
onde as famílias migrantes iam se abrigar, sabia onde se encontravam seus precários acampamentos de beira de estrada (as "hoovervilles" e as "Little Oklahomas") ${ }^{7}$ e onde paravam para abastecer, além de conhecer muitos dos Okies e Arkies $^{8}$ e saber falar seu peculiar dialeto.

Por intermédio de Collins, Steinbeck entrou concretamente no cotidiano dos acampamentos, ganhando acesso tanto aos moradores, às acomodações e aos expedientes de seu funcionamento, quanto aos meandros institucionais e administrativos envolvidos em sua manutenção. Ganhou também acesso aos ricos relatórios semanais que Collins escrevia disciplinadamente para a administração regional da Resettlement Administration, que ficava em San Francisco. Todos os que descreveram Collins parecem concordar que, ao lado de um arguto administrador, ele era um reformador incansável e um convicto acerca do potencial humanizador dos acampamentos, o que contribuiu para que seus relatórios fossem particularmente bem informados e simpáticos aos moradores. Robert DeMott escreveu sobre Collins: "Sua vívida prestação semanal de contas acerca das atividades dos trabalhadores, além de observações sobre episódios de seu cotidiano, sua dieta, seu lazer, seus dizeres e suas crenças forneceram um cativante suplemento documental às pesquisas" de Steinbeck. (STEINBECK; DeMOTT, 1990: p. xxviii) E o próprio Steinbeck, sobre Collins, escreveu em seu diário em 24 de junho de 1938: "Ele é tão bom. Eu preciso das anotações dele." (STEINBECK; DeMOTT, 1990: p. 33)

Em virtude da comunhão em muitos princípios e valores, Steinbeck e Collins se deram muito bem, e tornaram-se amigos para além da experiência de 1936. Collins visitou a casa dos Steinbeck em Los Gatos posteriormente, bem como viajaram os dois outras vezes, para que o escritor pudesse juntar material e impressões para o romance de 1939. DeMott comentou que Steinbeck chegou a intervir junto à Covici-Friede, editora que publicou Luta incerta, para que os

\footnotetext{
7 As "hoovervilles" eram assim chamadas em mordaz referência ao presidente Herbert Hoover (1929-1932); e as "Little Oklahomas" tinham esse nome pela grande presença de migrantes desse estado, o qual foi sobremaneira atingido pelos dust bowls.

${ }^{8}$ Os Okies eram os migrantes oriundos de Oklahoma; os Arkies, do Arkansas.
} 
relatórios do reformador pudessem ser publicados em forma de livro - algo que acabou não acontecendo em virtude da falência da editora algum tempo depois.

É razoável supor, também, que a camaradagem entre os dois tenha se reforçado devido à sombra sinistra da desolação que pesava sobre eles dia após dia. De fato, o "êxodo americano" da década de 1930 tornou-se um triste marco da história estadunidense, e a matéria que os artigos exploram, a realidade que Collins testemunhava diariamente, é terrível.

Um dos elementos que torna esses artigos de Steinbeck valioso documento histórico é o fato de que demonstram que as razões naturais concorriam ao lado de inúmeras outras para produzir aquele enorme contingente de despossuídos a migrar. A crise deflagrada em fins de 1929 catalisou uma darwiniana e cruel seleção das mais poderosas criaturas econômicas, favorecendo a sobrevivência dos capitais concentrados no campo, na indústria e no comércio, desbancando aqueles pequenos agentes econômicos encarnados, por exemplo, pelos pais de Steinbeck, pelos Joad e por tantos sujeitos que o escritor encontrou vivendo na provisoriedade dos acampamentos federais.

Correndo ao lado dos dust bowls, portanto, havia uma força tão plena de potencial destrutivo quanto aquela natural: a voragem da concentração capitalista. Dispensando a terminologia econômica ou marxista, e adotando aquele tom de sinceridade empírica que o fazia preferir o qualificativo "escritor" a "autor", Steinbeck destrinchou o novelo factual e afixou analiticamente as forças sociais, naturais, econômicas e políticas que compunham o panorama dos anos 30. A desenvoltura epistemológica com que a abordagem dos artigos é proposta exime Steinbeck de fazer pesar demais a mão retórica, mas não consegue evitar o desencadear de seu senso de justiça.

A série Os ciganos da colheita é marcada por aquela típica característica da percepção do escritor, que Benson de modo muito perspicaz chamou de "(...) grande dose de atenção às coisas pequenas que têm grande significado para as pessoas comuns". (BENSON, 1984: p. 166) Por meio dela é que detalhes aparentemente secundários são trazidos à tona, como utensílios de cozinha 
sujos, um chapéu esgarçado ou o inventário de uma mudança, e então realçados à condição de símbolo de um mundo e de um modo de vida em decadência.

É possível ver nos artigos as dimensões fundamentais da Grande Depressão, como que micro-retratos dela, os quais buscam fixar uma imagem da crise mas sobretudo uma leitura dela, uma que reconheça sua natureza social e histórica para além da fatalidade ambiental. Grosso modo, pode-se dizer que os temas dos sete artigos são: 1) a genealogia social, étnica e histórica dos "ciganos da colheita"; 2) situação dos acampamentos de beira de estrada (squatters' camps); 3) sistema e métodos de exploração dos "ciganos da colheita" pela agricultura californiana; 4) situação dos acampamentos federais (especialmente o de Arvin); 5) formas e (in)eficácia de assistência disponíveis às famílias migrantes; 6) dinâmica da exploração do trabalho agrícola na Califórnia com relação aos "estrangeiros" (chineses, filipinos, japoneses e mexicanos); e 7) possíveis encaminhamentos para a situação dos "ciganos da colheita".

A série de artigos abre com um retrato panorâmico do fenômeno a ser dissecado: "Nessa época do ano, quando as grandes plantações da Califórnia se aproximam do período da colheita (...) nossas rodovias se enchem de trabalhadores migrantes." (STEINBECK, 1988: p. 19) Muitos destes buscavam a Califórnia como alternativa, pois haviam perdido sua terra recentemente e a agricultura californiana desde há muito era pródiga em ofertas de trabalho, outrora realizado extensivamente por "estrangeiros". ${ }^{9}$ Os migrantes tornavam-se então os "ciganos da colheita": viviam andando, seguindo rastro do amadurecimento das plantações e pomares, movendo-se de colheita e colheita. Diante disto, ainda no primeiro artigo, Steinbeck apresenta seus dois

\footnotetext{
${ }^{9}$ A Califórnia tinha uma composição étnica particularmente heterogênea em relação ao restante dos Estados Unidos, e isso se deve ao histórico de ocupação da região. Até a década de 1840 ela havia sido território mexicano (do mesmo que até o século XIX fora possessão colonial espanhola), o que concorria para grande presença de mexicanos - a toponímia hispanófona do estado serve como indício disto. Nessa mesma década estabeleceu-se a chamada "Corrida do ouro" (Gold Rush), que trouxe grande contingente de populações de dentro dos Estados Unidos para a Califórnia, mas também de outros países da Ásia e da América do Sul e Central. Por fim, é preciso lembrar que a segunda metade do século XIX foi o palco de diversas campanhas nacionais pela imigração para os Estados Unidos, e que a Califórnia era um dos portos de entrada, sobretudo de japoneses, filipinos e chineses.
} 
argumentos principais: a) os "ciganos da colheita" de então eram "novos ciganos", isto é, migrantes de tipo distinto daqueles do passado; e b) eles (...) são ciganos por força das circunstâncias." (STEINBECK, 1988: p. 22)

Praticamente toda a argumentação dos artigos se arvora a partir dessa dupla tese. A comparação entre os métodos de exploração do trabalho agrícola do presente (artigo 3) e do passado (artigo 6) serve para ressaltar as continuidades e rupturas históricas do processo, tanto rastreando as distinções entre os migrantes quanto a semelhança das "circunstâncias" que os "forçam" à itinerância cigana. $\mathrm{O}$ cotejo entre a situação dos acampamentos de beira de estrada (artigo 2) e os acampamentos federais (artigo 4) descreve dois diferentes modelos de gerenciamento daquelas mesmas "circunstâncias", demonstrando como o primeiro as reforça e o segundo as mitiga. Por fim, à guisa de conclusão aos artigos, o artigo 7 propõe espécie de inventário das ações com resultados positivos, que restauram a "dignidade" dos "ciganos da colheita". Articulando-se à enunciação do problema nas primeiras linhas do primeiro artigo, as últimas linhas desse último artigo pontificam, entre ameaça e vaticínio:

Os novos migrantes que vêm à Califórnia fugindo dos dust bowls estão aí para ficar. (...) Podem ser cidadãos do melhor tipo, ou um exército acossado pelo sofrimento e pelo ódio a tomar aquilo de que precisam. Do seu tratamento futuro depende a ação que serão forçados a tomar. (STEINBECK, 1988: p. 62)

Por conta da sistemática organização desse cotejo, os artigos lançam mão de operações analíticas típicas das ciências humanas para dar conta de seu objeto. Ao descrever minuciosamente a alimentação, o vestuário, as habitações e os costumes que integravam o dia-a-dia dos acampamentos, ouve-se o eco das descrições densas típicas da Etnografia e da Antropologia. Ao reconhecer e explicar os diferentes patamares sociais dentro desses acampamentos, bem como as relações entre eles, ele se utiliza de elementos explicativos da Sociologia. Ao desenterrar e interpretar o processo pelo qual as outrora prósperas classes médias rurais estavam se tornando trabalhadores agrícolas aviltantemente explorados, Steinbeck se aproximou do cotejo da 
processualidade típico da Historiografia. E ao descrever a refrega políticoinstitucional em torno dos migrantes no Senado e na Câmara de Comércio, buscando entender sua correspondência com grupos sociais e interesses econômicos, flagramos o escritor a comportar-se como um cientista político.

Por causa da habilidade de recrutar os caracteres mais prosaicos dessa realidade para pô-los à serviço da grande análise é que Steinbeck consegue demonstrar as virtualidades profundas do comentário de um garoto indignado que encontrou nas peregrinações de 1936. Morador de um acampamento de beira de estrada, ele faz uma análise lapidar de sua situação: "Quando eles precisam de nós nos chamam de migrantes, quando acabamos a colheita, somos vagabundos e devemos ir embora." (STEINBECK, 1988: pp. 23-24) Steinbeck deixou as palavras na boca do garoto, não roubou-lhe o protagonismo nem o diluiu na vaidade de um argumento próprio, tampouco na apatia da condição de objeto jornalístico. Se recusou a tomar parte na dilapidação de sua já tão aviltada humanidade.

O modo visceral com que essa humanidade é descrita aponta para algo mais do que um compromisso ideológico distante. Aliás, Steinbeck se irritava quando tentavam-lhe encaixar nas arcadas abstratas do firmamento filosófico, como se vê numa carta que enviou a Merle Danford em outubro de 1938, a quem cedera à contragosto uma entrevista:

Cara senhorita Danford,

(...) Quanto à pergunta sobre o que eu quero dizer com - ou qual é minha filosofia - eu não faço a menor ideia. Se eu lhe dissesse uma, não seria verdade. Eu não gosto que as pessoas sejam machucadas, passem fome ou fiquem tristes de modo desnecessário. É simples assim. Me desculpe por não entrar numa discussão erudita. (STEINBECK; FENSCH, 1999: p. 27)

Noutros termos: os migrantes que figuram na série "Os ciganos da colheita" não eram mero escopo para Steinbeck expressar posições políticas ou filosóficas, tampouco simples matéria para escalar a atenção jornalística que o assunto vinha tendo recentemente. O que ele descobriu na viagem de 1936 é que os trabalhadores que povoavam os discursos radicais nos anos 30 eram parentes de seus próprios antepassados. O laço que os unia ganhou relevo 
quando as contradições do desenvolvimento econômico pregresso se tornaram agudas a partir de 1929, ao passo que argumentamos que a descoberta desse parentesco foi momento fundamental na transformação da visão de Steinbeck e sua obra literária.

\section{A literatura de John Steinbeck e o papel dos migrantes}

Pensados em perspectiva, os artigos de 1936 constituem um divisor de águas na obra literária de Steinbeck dessa década: de um lado ficam os primeiros (e franzinos) arranques do início dos anos 30; do outro, a possante escalada até o cume de 1939. Em termos de seriedade política, compromisso humanista e destreza de ofício, esses artigos foram cruciais para que Steinbeck alcançasse sua estatura como escritor.

Basta cotejar suas obras de antes e depois de 1936 para atestá-lo.

Até aquela altura da década de 30, Steinbeck havia escrito cinco livros, e somente um deles, Luta incerta (In dubious battle), de janeiro de 1936, pode ser caracterizado como tendo algum tipo de compromisso político mais robusto, que atinasse de forma direta às questões históricas e sociais da Grande Depressão que o tornaram um clássico.

O primeiro destes, As pastagens do céu (The pastures of heaven), de 1932, é mais um livro de contos semi-conectados por se passarem num mesmo local, o vale Coral de Tierra, na Califórnia, do que por ser um romance de tipo clássico. Numa estrutura que lembra muito o Winesburg, Ohio (1919) de Sherwood Anderson, ou mesmo o Spoon River Anthology (1915) de Edgar Lee Masters, prevalece nele a busca pelo pitoresco na trajetória dos personagens, quase todos "tipos locais", tornando-o uma espécie de "romance de costumes" provinciano. Isso tudo convive lado à lado com a celebração bucólica da paisagem da infância de Steinbeck, como indica o título do livro.

O livro seguinte, $O$ menino e o alazão (The red pony), é uma novela costurada a partir de contos. Ela foi publicada em 1937, mas é formada de histórias escritas entre 1933-1934, motivo pela qual ela pertence à primeira 
metade da década de 30 . Nela prevalece a atmosfera contemplativa, dessa vez seguindo a faina cotidiana de uma pequena fazenda, entremeada com a nostalgia das memórias de infância do próprio Steinbeck, filho da terra como o protagonista Jody. Ouvindo as histórias do avô, que fizera a travessia continental no final do século XIX, ou acompanhando a destreza do peão da fazenda nas suas tarefas cotidianas, esse talvez seja o livro do escritor com a mais intensa dose nostálgica. Cada elemento literário funciona como um tijolo na construção desse retrato da união orgânica entre homem, terra e trabalho. A pequena propriedade ergue-se nela como a base essencial de todo um modo de viver, aquele das antigas classes médias rurais que desde fins do XVIII constituíam a seiva política e ideológica dos reclames jeffersonianos.

Segue-se a esse livro o primeiro romance propriamente dito do escritor, Ao deus desconhecido (To a god unknown), também de 1933. Ele conta a história de pequeno fazendeiro Joseph Wayne em sua batalha contra uma seca que assolou a Califórnia, recobrindo-a de dimensão mítica ao unir o modo de vida dos pequenos proprietários californianos a certo culto da fertilidade pagão, e ornando-a com pesado simbolismo bucólico, com árvores e touros totêmicos. Aqui, a unidade de homem e terra é elevada ao patamar espiritual, a catarse se dando quando Joseph, do alto de uma pedra em forma de altar, fere o pulso e vê seu sangue escorrer sobre o solo no momento mesmo em que caem as primeiras gotas da tão esperada chuva. Daquele ponto climático, o protagonista exclama a epifania: "Eu sou a terra (...) e eu sou a chuva. O capim crescerá de mim dentro em breve." (STEINBECK, 1981: p. 178)

Em 1935, na novela Boêmios errantes (Tortilla Flat), uma primeira modificação se opera quando os protagonistas deixam de ser os pequenos proprietários e fazendeiros californianos e tornam-se os paisanos, os trabalhadores mexicanos marginais de Monterey. O livro é uma narrativa entre satírica e picaresca sobre a vida boêmia e profundamente humana desse grupo social, na qual Steinbeck, avesso a certas convenções sociais tradicionais, torna os paisanos seus heróis cômicos, espécie de caricaturas dos Cavaleiros da Távola Redonda do livro de Thomas Malory, de que tanto gostava. 
A mudança de protagonistas vem acompanhada de uma outra, muito sutil, que é a incorporação do que poderíamos chamar de "motivos sociais". Os paisanos eram trabalhadores provisórios da indústria de enlatados de Monterey, e vivem entre períodos de dedicação regular a esse emprego e temporadas de ócio, além de aplicarem pequenos golpes para sustentarem seus costumes boêmios. A aparição desses personagens, dado o histórico de ocupação da Califórnia e a recente deportação de centenas de milhares de mexicanos, ${ }^{10}$ expressa uma mudança de perspectiva política da parte de Steinbeck, uma rumo à esquerda. Ao usar a literatura para cobrir esses sujeitos sociais com o manto da ambiguidade moral, afinal eram vagabundos vivendo numa sociedade muito alinhada à ideologia moral do trabalho, Steinbeck dava um passo para além do passado idílico e assumia posição diante de questão do presente.

Para futura referência, dizemos: é aqui que está encravado o ano crucial de 1936.

Depois da jornada como repórter no verão desse ano, Steinbeck escreveu a novela Ratos e homens (Of mice and men), publicada em 1937, um visceral mergulho na vida de dois trabalhadores rurais, George e Lennie, que perambulam pela Califórnia em busca de trabalho e da realização do sonho de se emanciparem da condição de despossuídos. Carregando muitas das características dos migrantes e dos peões de fazenda que o escritor conhecera, a dupla de Ratos e homens errava em precariedade, constituindo o oposto da estabilidade que o enraizamento das pequenas propriedades proporcionava. Se antes os protagonistas de Steinbeck estavam muito bem ancorados em seu modo de vida, a ponto de confundir-se com ele, no livro de 1937 isso só existe como horizonte, conforme expresso na fala de Lennie:

- E a gente pode tê uns porco. (...) a gente vai podê defumá o toicinho e o presunto, e fazê lingüiça e um monte de coisa

\footnotetext{
${ }^{10}$ Entre 1929-1936, sob o clima de insegurança e crescente xenofobia que se espalhou após a deflagração da crise econômica, uma campanha de deportação foi movida contra os mexicanos residentes em território norte-americano. As estimativas variam muito, mas giram entre $500 \mathrm{mil}$ e quase 2 milhões (BALDERRAMA; RODRÍGUEZ, 1995). Somente na Califórnia, que era território mexicano até meados do século XIX, foram 400.000 pessoas deportadas ou coagidas a deixar os Estados Unidos. (STATE OF CALIFORNIA, 2005) Em 7 de outubro de 2005 foi aprovado o pedido de desculpas oficial do Estado da Califórnia pelo "Programa de Repatriamento" dos anos 1930.
} 
assim. E quando os salmão subi o rio, a gente pode pegá uns cem e guardá no sal ou defumá. (...) Quando as fruta amadurecê, a gente pode fazê conserva (...) A gente vai vivê bem lá. A gente vai fazê parte daquele lugá. Num vai mais precisá ficá rodando pela região e comê comida de cozinheiro japa. Nada disso, a gente vai tê nosso lugá, e a gente vai fazê parte dele, e num vai tê que dormi em casa de pião nenhuma. (STEINBECK, 2007: pp. 82-83)

Em 1938 é publicada uma coletânea de contos, $O$ vale sem fim (The long valley), quase todos eles escritos entre o verão de 1933 e o de 1934, e que, como tal, carregam uma ambiguidade que evidencia os germes da metamorfose de Steinbeck ainda incubados, mas a debater-se. A coletânea foi publicada por convite do editor e amigo de Steinbeck, Pascal Covici, e reuniu parte substancial da ficção curta da época em que o escritor trabalhava disciplinadamente para conseguir publicar seus contos e contribuir para o orçamento da casa, então sustentado somente por sua esposa, Carol. É difícil encontrar um ponto de convergência temática ou mesmo formal entre os contos, pois eles "(...) foram produzidos em diferentes períodos e a maioria deles publicados independentemente", tendo servido, conforme argumentou o crítico John Timmerman, "como uma espécie de aprendizado literário" para Steinbeck. (In: STEINBECK, 1995: pos. 91 e pos. 237 , respectivamente) ${ }^{11}$

Se de um lado constam no volume algumas das histórias que compunham $O$ menino e o alazão, marcadas pelo tom romântico e saudosista da era pregressa; há outro como "A perdiz branca" ("The white quail"), um conto que se passa no ambiente doméstico e tradicional dessa mesma era, mas tratando-a como redoma moral que podia obstruir a visão dos pequenos fazendeiros. Além destes, há também um conto sobre um linchamento ("O vigilante", "The vigilante"), baseado no episódio em que Brooke Heart foi linchado por uma multidão em San Jose, em 1933, e outro ("Johnny Bear"), em que se pode ver uma prefiguração do gigante simplório Lennie, de Ratos $e$ homens.

\footnotetext{
${ }^{11} \mathrm{O}$ uso de "posição" (pos.) ao invés de "página" (p.) se dá aqui em virtude de a edição usada ser de um e-book ao invés de um livro impresso, e lida no dispositivo Kindle, o qual usa dessa categoria de referência.
} 
Em $O$ vale sem fim vivem ainda os ecos da antiga literatura nostálgica de Steinbeck, marcadas, no entanto, por preocupações políticas menos inocentes, em franca expansão e adensamento no interior de sua escrita. Timmerman afirmou que "(...) os contos de 1933-1934 foram um canteiro de testes para vários dos padrões temáticos de Steinbeck, alguns dos quais moldaram os romances da década de 1930." (In: STEINBECK, 1995, pos. 268275)

A escalada literária da década é coroada em 1939, com a publicação de As vinhas da ira, onde se testemunha um escritor maduro, cônscio das potencialidades dramáticas e das responsabilidades políticas de sua arte, capaz de operar em níveis tão distintos quanto subjetividade íntima e totalidade socioeconômica, fazendo-os retroalimentarem-se de seus dilemas e tragédias constantemente. A estrutura do livro, a firme costura de seus detalhes, faz ressoar na trajetória da família Joad o êxodo de um povo e a derrocada do universo cultural de uma geração inteira de americanos, demonstrando em sua anatomia o longo processo de amadurecimento de Steinbeck como leitor de realidade e escritor de ficção.

Por debaixo de personagens e enredo perambulam pessoais reais que Steinbeck conhecera, mas também o estofo dos arquétipos literários que ele digerira na sua longa maturação: há o pregador que perdeu a fé, a gênese do radicalismo dos anos 30, a moldura da peregrinação de Bunyan, a catarse quase folclórica do sonho americano virando pesadelo. Como exemplar de boa ficção, mescla o factual e o inventado de modo engenhoso, sem anulá-los entre si mas equilibrando-os sobre a caprichosa dialética da verossimilhança. Por meio de tal devassa, propõe uma explicação à realidade, na qual se enraíza uma leitura analítica; mas propõe também uma interpretação dela, que a alça quase ao domínio do mítico. A apreciação de Stoddard nesse sentido é precisa:

O mito que o anima [As vinhas da ira] é aquele do Jardim e da luta do homem por retornar a ele. Os pequenos fazendeiros de Oklahoma e dos estados adjacentes foram expropriados de sua terra pela seca e pela execução das hipotecas. A primeira é uma antagonista cósmica: o vento e a poeira memoravelmente evocados no capítulo de abertura, carregando reminiscências daquele incorpóreo antagonista d'A terra devastada de Eliot 
(...). O segundo antagonista são os bancos. O sistema que eles constituem é o principal alvo da ira de Steinbeck. (STODDARD, 1984: p. 67)

Enquanto nos primeiros livros prevalecia o tom contemplativo, uma dose de energia foi inoculada em Steinbeck por volta de meados da década de 1930, fazendo-o tornar-se o poderoso romancista da epopeia dos Joad, retratista por excelência desse momento trágico da história estadunidense, a ponto de ser universalmente citado como um documento histórico para compreender da Grande Depressão.

Em tempo, retomamos a marcação cronológica feita algumas páginas atrás, quanto ao ano de 1936. Algo se passara com Steinbeck então, e nosso argumento é de que a experiência do verão desse ano foi momento-chave da mudança.

Todos os biógrafos de Steinbeck e estudiosos de sua obra (Jackson Benson, Jay Parini, Robert DeMott, Warren French, Peter Lisca, Susan Shillinglaw etc.) concordam que Carol Henning Steinbeck, com quem o escritor casara em 1930, foi uma influência perene ao longo da década - motivo, aliás, pelo qual As vinhas da ira é dedicado primeiramente a ela. Carol ajudou no orçamento doméstico de modo a permitir o isolamento criativo que Steinbeck requeria, datilografou cada um dos manuscritos dele, e foi quem, aliás, sugeriu o título do romance de $1939 !^{12}$

Muito provavelmente foi também Carol quem concorreu como influência determinante para que um livro tão distinto como Luta incerta, no limiar entre a primeira e a segunda metades da década de 1930, pudesse ser escrito por Steinbeck. Por conta da atenção cuidadosa que devotava à vida e à política nacionais, pelo fato de que era pesquisadora do Emergency Relief Administration, ${ }^{13}$ bem como pelas pessoas que introduzia no círculo de amigos

12 Conforme carta de John Steinbeck a Annie Laurie Williams, julho de 1938. (In: STEINBECK; DeMOTT, 1990: p. xxvi)

${ }^{13}$ Criado em 1933, o Emergency Relief Administration (ERA) era um dos órgãos do New Deal que buscava lidar com o desemprego que se disseminou após 1929, primariamente por meio da criação de empregos para trabalhadores não-especializados em obras do públicas locais e estaduais; e mais tarde, em 1935, rebatizado como Works Progress Administration (WPA), por 
do casal, Carol acabou por trazer o marido para a órbita do engajamento político mais firme. DeMott afirmou que ela "(...) ativamente apoiou membros fugidos dos movimentos de trabalhadores rurais antes que Steinbeck o fizesse" (STEINBECK; DeMOTT, 1990: p. xxv); e Jay Parini escreveu que "De vez em quando, Carol (...) levava Steinbeck aos encontros furtivos de um grupo de socialistas que conhecera (...) por intermédio de um amigo do [The San Francisco] Chronicle." (PARINI, 1998: p. 104) Uma amiga do casal, Katherine Beswick, chegou a dizer: "Acho que ela era a consciência de John naquele tempo". (PARINI, 1998: p. 116)

À luz desses fatos, é preciso dizer que o romance Luta incerta e os artigos de 1936 que lhe seguiram de perto não foram raios num céu azul. Desde 1934 há anotações nos diários de Steinbeck mencionando um livro em que ele trabalhava e ao qual ele se referia simplesmente como "o livro da falange" ("the phalanx book"). (BENSON, 1984: p. 275) Tratava-se de uma narrativa cuja trama central girava em torno de uma greve de trabalhadores rurais, cujo movimento levava o portentoso nome de "falange" (e que mais tarde se tornaria o genérico "Partido" de Luta incerta).

Também de 1934, escrito entre o final de maio e início de junho, é o conto "O ataque" ("The raid"), incluído na coletânea de 1938, O vale sem fim. Ele trata de uma reunião de trabalhadores grevistas sendo desbaratada por "vigilantes" locais, no qual se discutem ideais de sacrifício individual e justiça coletiva. Baseada em episódios de "vigilantismo" local ocorridos no Imperial Valley na Califórnia, esse conto expressa bem o aspecto hesitante com que Steinbeck se aproximava de temas mais imediatamente políticos. As pessoas, organizações e agendas políticas que aparecem no conto não permitem verificação, pois são todas vagas, insinuadas. Imagina-se flagrar correspondências objetivas, mas os elementos todos do conto são recobertos de ambiguidade, provavelmente misto de deliberada precaução e um acanhamento que ainda se impunha entre o escritor e a matéria de sua ficção, sobretudo dadas

meio do emprego de milhões de trabalhadores em obras públicas federais que iam desde estradas a pontes, de ruas a aeroportos. 
as suas ressonâncias políticas. O resultado é um conto em que há vontade de solidariedade com os dois personagens Dick e Root, este um radical tarimbado aquele um neófito, mas tomado de falas que soam descarnadas, presas de uma grandiloquência que as torna abstratas, muito diferentes da clareza coloquial dos personagens de Ratos e homens, de As vinhas da ira ou então do garoto d'Os ciganos da colheita", supramencionado. Nota-se isso quando Root tenta preparar o novato para a agressão dos "vigilantes", que está à caminho:

Controle-se, garoto! E não se esqueça de uma coisa: se alguém o espancar, não é ele que o está fazendo, mas sim o Sistema. E não é em você que está batendo. Ele está simplesmente tentando destruir o Princípio. É capaz de se lembrar disso? (STEINBECK, s.d.1: p. 89, grifos nossos)

Diante do ataque que figura no título do conto, feito pelos "vigilantes" locais contra os grevistas, a fala que Steinbeck põe na boca de Root soa pouco verossimilhante. Há nela um apelo à solidariedade de classe, mas que acaba escorregando para o universalismo cristão, ao fim muito aparentado à frase proferida pelo Cristo crucificado no Gólgota, prestes a consumar seu sacrifício fundamental:

Camaradas, vocês são homens iguais a nós! Somos todos irmãos... (...) Será que vocês não entendem? É tudo por vocês! Estamos fazendo tudo isso por vocês! Tudo isso, entendem? Vocês não sabem o que estão fazendo! (STEINBECK, s.d.1: p. 91, grifos nossos)

Desde 1934, portanto, vemos os "motivos sociais" ganharem força na literatura de Steinbeck, fosse com os paisanos, com os contos sobre vigilantismo e sobre trabalhadores grevistas, e também com o gradativo afastamento do saudosismo de sua primeira literatura, trocado por um encarar mais frontal de situações do presente. $\mathrm{O}$ tom mais próximo ao conservadorismo, do início da década, ia se radicalizando conforme ela avançava.

Steinbeck refinava sua percepção acerca das condições em que a economia e a vida social estadunidenses giravam, e sua longa gestação política estava pronta a amadurecer quando estreitou laços com figuras políticas mais radicais. Francis Whitaker, entusiasta político e frequentador do círculo de amizades dos Steinbeck, apresentou o escritor a Ella Winter, Lincoln Steffens, 
Anna Louise Strong e Mike Gold, além de diversos outros nomes de seu entourage. Um destes foi justamente James Harkins, "(...) um jovem hortelão cultivador de alface que se tornara um líder e organizador trabalhista no Imperial Valley desde a greve do inverno de 1934 e a greve da alface de Salinas, em 1936" (BENSON, 1984: p. 294) Charles Wollenberg afirmou que Harkins está na base do romance Luta incerta. (In: STEINBECK, 1988: p. vi)

Foi essa a genealogia do romance de 1936 e da sua trama, que orbita ao redor de uma greve de apanhadores de frutas em Torgas Valley. É daí também sua vontade de conquistar simpatia por aqueles trabalhadores que já vinha timidamente tornando personagens de suas estórias, ora como heróis cômicos (Boêmios errantes), ora como heróis trágicos ("O ataque").

Apesar de a primeira edição de Luta incerta conter na capa os dizeres "Um romance de John Steinbeck, autor de Boêmios errantes", o livro representava de um novo passo literário e político da parte do escritor, aprofundamento da ruptura com o tom nostálgico de sua primeira literatura, o que tornava os dizeres da capa tanto propaganda quanto aviso. Na edição de 2 de fevereiro de 1936 do The New York Times, o resenhista do jornal chegou a declarar: "Você jamais saberia que Luta incerta é do mesmo Steinbeck se os editores não tivessem lhe dito." (MARSH, 1936, s.p.)

Em face disto, pode parecer que foi o romance Luta incerta (janeiro de 1936), antes dos artigos do The San Francisco News (outubro de 1936), o que catalisou a mudança de perspectiva da literatura de Steinbeck, mas dizê-lo seria ignorar que a "luta" que Steinbeck estava iniciando ainda lhe parecia "incerta". Seu amadurecimento político era visível, mas os grevistas do romance de 1936 eram mais decalques de sujeitos presentes no discurso dos radicais com quem Steinbeck passou a conviver do que personagens verossímeis, de "carne e osso". Tinham entranhas antes teóricas do que empíricas, poderíamos dizer.

Luta incerta está cheio de personagens com falas muito panfletárias, parecendo tiradas do discurso de um líder sindical ou partidário. Tornou-se comum afixar-lhe a etiqueta de "romance proletário", por vezes até de "propaganda", por essa razão. Ainda que se considere que um de seus 
personagens é de fato um líder radical, Mac, abundam exemplos passagens caracterizadas por esse aspecto, vindas também de outros personagens, como o seguinte diálogo:

- Quem produz todos os bens? - perguntou Joy.

- Ora, os trabalhadores, é claro. (...)

- E quem fica com os lucros?

- As pessoas que investiram o capital.

- Mas eles não produzem nada! - gritou Joy. - Que direito têm então de ficar com os lucros? (STEINBECK, s.d.2: p. 22)

Se pode verificar algo parecido também na conversa entre Jim, o protagonista, e um velho que viera a Torgas para participar da colheita:

- Ganhei algumas coisas enquanto trabalhava - disse ele [o velho]. - Eu subia num tronco de trinta metros e sabia que o dono da serraria e o presidente da companhia não tinham coragem de fazer a mesma coisa. Só que eu tinha! (...) Tive as minhas satisfações...

- Mas eles ficaram com todos os lucros do seu trabalho. Ficaram ricos à custa de seu trabalho. E quando você ficou velho demais para continuar a subir nas árvores, simplesmente deram-lhe um pontapé no rabo.

- Tem razão, garoto, foi isso mesmo que eles fizeram. (STEINBECK, s.d.2: p. 66)

O livro todo parece ser uma tentativa de Steinbeck de persuadir os outros, e provavelmente a si mesmo, da justeza dos meios radicais de luta. Decerto estava acostumado a solidarizar-se com trabalhadores, pois convivera com eles quando trabalhou em fazendas nas cercanias de Salinas, e a "filosofia" que confessara na carta de 1938 também ajudava nesse sentido, mas seu patriotismo conservador de classe média, seu tradicionalismo, por assim dizer, pareciam impedi-lo de endossar os trabalhadores quando esses empreendiam ações políticas mais radicais. Para além da referência miltoniana do título, aludindo à eterna e temerária batalha do homem contra a injustiça, é esse o caráter "incerto" da "luta".

Isto encontra seu eco na estrutura do livro, pois do mesmo modo que Steinbeck se aventurava no universo da luta dos trabalhadores, tateando em busca da verossimilhança e da calibração de seu humanismo rústico àquela pauta política, também o protagonista Jim Nolan é um recém-chegado, receoso mas com vontade de fazer algo pela causa. Há uma passagem no livro que 
expressa isto, se dá quando Dakin, um dos líderes grevistas, descreve o estado de espírito dos apanhadores amotinados: "(...) todos estão furiosos, embora não tenham a menor ideia do que possam fazer." (STEINBECK, s.d.2: p. 78) Talvez menos desorientado que os apanhadores "furiosos", era provavelmente assim que Steinbeck se sentia: seus brios morais se inflamavam diante da exploração dos trabalhadores, mas se chocavam com certos valores políticos quando se entrava no terreno da ação. Seu coração estava no lugar certo, mas sua razão ainda precisava ser convencida.

Argumentamos que o que permitiu a Steinbeck ser persuadido, injetando verossimilhança e sinceridade nos personagens, fazendo seus dizeres soarem mais naturais e menos arquetípicos, foi o conjunto de experiências como repórter na segunda metade de 1936. A passionalidade arrebatadora da literatura de Steinbeck entre 1937-1939, assim como o senso de justiça e o compromisso existencial expressos em As vinhas da ira nasceram a partir da experiência do verão daquele ano.

É possível dizer que essa mudança se deu porque o escritor foi posto diante da urgência de pessoas reais ao invés da distância de ideias num debate, mas sustentamos que foi sobretudo porque suas viagens the revelaram um parentesco pesaroso: os despossuídos de beira de estrada, aqueles que eventualmente se erguiam como grevistas e líderes radicais, eram os mesmos sujeitos que ele transformara em personagens nos livros que escrevera na primeira metade dos anos 30. Isto é: o heróico Joseph Wayne de Ao deus desconhecido e o faceiro Jody Tifflin de $O$ menino e o alazão são os mesmos trágicos Lennie Small de Ratos e homens e Tom Joad de As vinhas da ira, só que em momentos diferentes da evolução histórica das antigas classes médias rurais estadunidenses.

Esse é um dos pontos mais ressaltados por Steinbeck nos artigos d'Os ciganos da colheita", a primeira parte da dupla tese que apontamos algumas páginas atrás, isto é, de que aquela procissão de centenas de milhares era constituída de "um novo tipo de migrantes" (STEINBECK, 1988: p. 21):

Os antigos migrantes, os estrangeiros, foram invariavelmente retirados de uma classe de peões, mas não é esse o caso dos 
novos migrantes. Eles são pequenos fazendeiros que perderam suas terras ou trabalhadores agrícolas que viviam com suas famílias no antigo estilo americano; homens que trabalharam duro em suas próprias fazendas, que sentiram o orgulho de possuir uma terra e viver em contato direto com ela. São americanos engenhosos e inteligentes, que atravessaram o inferno da seca e que viram suas terras murcharem, morrerem e terem sua superfície varrida. (STEINBECK, 1988: p. 22)

Noutro momento escreve:

Eles têm resistido e podem resistir muito mais, pois seu sangue é forte. Eles são descendentes dos homens que cruzaram o meio-oeste, que conquistaram suas terras lutando, que cultivaram as planícies e nelas ficaram até que elas voltassem a ser deserto. Devido à sua tradição e ao seu treinamento, eles não são migrantes por natureza, eles são ciganos por força das circunstâncias. (STEINBECK, 1988: p. 21)

Insiste, afirmando que "(...) eles são gente americana", que seus "nomes (...) indicam que descendem de ingleses, alemães e escandinavos. Há Munns, Holbrooks, Hansens, Schmidts." (STEINBECK, 1988: p. 23) Quase se pode escutar nas entrelinhas o pensamento do escritor, de origem germano-irlandesa, supondo que poderia haver algum Steinbeck ali, a errar pela estrada.

A origem deles foi desencavada pelo escritor: se deve ao "(...) fato de o antigo grupo de trabalhadores, mexicanos e filipinos, estar sendo deportado e repatriado muito rapidamente, enquanto, por outro lado, o caudal de refugiados dos dust bowls aumenta constantemente". (STEINBECK, 1988: p. 21) O "Programa de Repatriamento" dos anos 30 estava por detrás dessa diminuição de mão-de-obra mexicana e filipina, tendo concorrido para abrir as fileiras de mão-de-obra barata para braços americanos (verdadeiro exército industrial de reserva, como demonstra As vinhas da ira). A crise econômica criou as condições tanto para o crescendo de insegurança que favoreceu a xenofobia (e eventualmente a adoção da política de deportação) quanto para a disponibilização desse novo tipo de mão-de-obra.

A constatação do parentesco histórico entre os "novos migrantes" e as antigas classes médias rurais implicou numa diferença monumental, e uma que distingue não somente a literatura da primeira e da segunda metade dos anos 
1930, mas também o romance Luta incerta dos artigos jornalísticos de outubro de 1936. Essa constatação pode explicar porque os personagens do conto "O ataque" (de 1933-1934) falam sobre seu adversário chamando-o genericamente de "Sistema", ou porque o "Partido" de Luta incerta é tão indefinido e a arquitetura de sua trama tão esquemática: eles eram mais inércia dos debates políticos em que Steinbeck tomara parte no seu círculo de amizades do que fruto de uma convicção visceral do escritor. Ambos o conto e o romance são evidências de uma crescente simpatia de Steinbeck pelos despossuídos e por uma causa mais radical, mas uma que era tímida, por vezes protocolar, rapidamente diluída num humanismo abstrato, mais casca que substância.

A afeição do escritor, que se encontrava lateralmente nesses personagens, manifestava-se com abundância sincera quando ele falava sobre a sabedoria rústica de Billy Buck (em $O$ menino $e$ o alazão) ou sobre um motorista que para seu ônibus no intuito de contemplar a majestade do vale de Salinas (em As pastagens do céu). Por isso é que, quando suas jornadas como repórter lhe permitiram perceber que o rapazola Jody de 1933 era da mesma cepa do líder grevista Jim Nolan de 1936, a afeição e a solidariedade que nutria por aqueles personagens d'antanho podia se estender também sobre os despossuídos e radicais de então. Essa solda foi fundamental para sua constituição como escritor, bem como foi para que sua obra pudesse obter a envergadura histórica que granjeou.

A experiência do verão de 1936 também deu novo sentido ao nostalgismo da literatura da primeira metade da década, impedindo que ele se fechasse sobre si mesmo ou, então, que desembocasse em conservadorismo político. Aquele passado idílico foi recrutado em nome de uma causa democrática, crescentemente radical, cuja função era servir de parâmetro e pôr em causa o estado de coisas do presente do escritor. É assim que o passado aparece em As vinhas da ira, como na fala de Ma Joad:

- Nós somos os Joad. O avô de nosso avô combateu na Revolução. A gente era dono de uma fazendinha, até que ficou cheio de dívidas. Então...então veio aquela gente [do banco]! Que mal eles faziam! Cada vez que eles vinham, parecia que tavam dando em mim...em todos nós. (...) Eu me 
sentia miserável, me sentia com vergonha. (STEINBECK, 1972: p. 420)

A situação antes compartilhada por esses então-migrantes, fosse quanto à propriedade da terra ou ao papel que haviam desempenhado historicamente, passava a servir como um elemento de identificação social e política. Ela criava condições para reivindicar o patriotismo num sentido popular, instando-o a cumprir suas promessas e reconhecer como dever nacional o zelo pelos despossuídos. De modo similar, criava condições para divisar inimigos comuns: os bancos, as empresas agrícolas, os especuladores imobiliários - o capital financeiro, enfim. A famosa grassroots democracy jeffersoniana, que desde o século XIX estabelecera a correlação fundamental entre "democracia econômica" e "democracia política" centrada na pequena propriedade (GATES, 1941: p. 61), passou a ser então invocada como ferramenta de luta, como um possível freio às rodas do capitalismo financeiro.

O economista Leon Keyserling, que trabalhou durante as administrações de Roosevelt envolvido com o programa do New Deal, reconheceu isto numa discussão sobre a "Revolução keynesiana" em 1972. Segundo ele, a tradição política radical dos Estados Unidos teve papel mais determinando que o de Keynes na construção do programa de reestruturação econômica:

Em essência, o New Deal se tornou factível pelas condições sociais e políticas daquele tempo e pelo advento de grande liderança. Mas seu conteúdo específico já estava na experiência americana: o movimento de lavradores e de trabalhadores, o movimento Populista [de 1890], alguns aspectos de William Jennings Bryan, o período de reformas de Woodrow Wilson, os ensinamentos de Henry George sobre redistributivismo, os muitos anos de pregação dos partidos Socialistas, o grande número de associações voluntárias devotadas a várias reformas sociais [etc.] (...). Com todo o respeito a Keynes, eu não pude encontrar evidência razoável de que o New Deal teria sido muito diferente se ele não tivesse participado (...) (KEYSERLING; ROBERT; CURRIE, 1972: p. 135)

Os migrantes dos quais Steinbeck falou em seus artigos expunham de modo particularmente agudo as contradições do capitalismo estadunidense. Mostraram que a lógica que o guiava era a da rapina, e que as classes 
dominantes não poupariam pequenos proprietários e lavradores por conta de algum escrúpulo patriótico. Mais do que isto, os migrantes constituíam uma força social e política que prometia desequilibrar a correlação de poderes, e a frase final do último artigo de Steinbeck deixa isto muito claro: eles "Podem ser cidadãos do melhor tipo, ou um exército acossado pelo sofrimento e pelo ódio a tomar aquilo de que precisam." (STEINBECK, 1988: p. 62) Há nisso a radicalização de um jeffersoniano e os temores de um antigo conservador dando um passo político à frente. Se é possível dizer que isso estava aquém da revolução, é forçoso reconhecer que estava muito além do projeto liberal que estava indo à pique.

\section{Considerações finais}

A experiência do verão de 1936 permitiu a Steinbeck constatar que não se tratava da decadência de qualquer mundo ou de qualquer modo de vida, mas precisamente dos seus, aqueles de seus pais e avôs, do qual ele era pretenso herdeiro. O que aquelas semanas na estrada lhe revelaram é que os despossuídos que habitavam o discurso dos políticos radicais não eram uma raça estrangeira ou alguma classe etérea, mas sim seus próprios antepassados, seus vizinhos, parentes e amigos, as pessoas no meio das quais havia crescido.

Nos artigos podemos ver essa questão sendo dolorosamente constatada por Steinbeck, cuja dor, no entanto, seus brios "casca grossa" só permitiam sair em forma de uma indignação firme, contundente. A solidez de seu engajamento e o rigor de suas observações parece ser uma variedade daquele tributo feudal, a "mão-morta", o qual ele tinha de pagar para poder reclamar sua herança.

Por esse caráter, inclusive, é que os artigos permitem entrever outra das árduas realidades dos trabalhadores estadunidenses: a dificuldade de união política outorgada pela heterogeneidade de suas origens nacionais e étnicas. Mesmo um irremediável democrata como Steinbeck se vê algumas vezes estabelecendo patamares de importância desiguais aos americanos e aos outros, sejam eles chineses, japoneses, filipinos ou mexicanos. Por vezes se tem a 
impressão de que a solidariedade recai sobre esses últimos lateralmente, somente na medida em que também as antigas classes médias rurais se proletarizaram. Como Roediger demonstrou no seu The wages of whiteness (ROEDIGER, 2007), a etnia é fator fundamental na construção da classe trabalhadora estadunidense, um recorrente obstáculo à sua organização política, e Steinbeck parecia não estar livre, em seu patriotismo jeffersoniano, de padecer das armadilhas dessa questão.

O que os migrantes dos anos 30 expunham, que Steinbeck foi capaz de captar e expressar, é como a Grande Depressão transformou a composição da classe trabalhadora pela injeção de grandes contingentes das antigas classes médias em seus baixios sociais. Expunham também como a insegurança que surgiu no rescaldo da crise estourou primeiro sobre os trabalhadores considerados "não-americanos", que foram deportados "de volta" para seus países na década de 1930 (muitos deles jamais haviam morado nesses países). Os migrantes expunham, ainda, quão humanamente destrutiva foi a crise de 1929, e que aquilo que eufemisticamente se chama de "ajuste do mecanismo de oferta e demanda" é um gerador de crises em potencial, onde se expressam as tensões formativas da dialética socioeconômica. Expunham, por fim, a ambiguidade política do credo nacional dos Estados Unidos, que em sua complexidade abriga ao mesmo tempo grande dose de conformismo à hegemonia capitalista e um robusto manancial de crítica social e radicalidade política.

O que se pôde observar analisando o processo de constituição da literatura de Steinbeck ao longo da década de 1930 foi a gradativa constatação dele acerca dessas transformações históricas. Das pretensões em torno de uma inocência nostálgica que se verifica nas primeiras obras (As pastagens do céu e Ao deus desconhecido, p.ex.) até o monumental romance social de fechamento da década, As vinhas da ira, pode-se perceber que a experiência de 1936 foi um momento crucial, quando a experiência do jornalismo calibrou a voz do romancista. 


\section{Referências}

BALDERRAMA, Francisco E.; RODRÍGUEZ, Raymond. Decade of betrayal: Mexican repatriation in the 1930s. Albuquerque: University of New Mexico Press, 1995.

BENSON, Jackson. The true adventures of John Steinbeck, writer. New York: Penguin Books, 1984.

DUNCAN, Dayton; BURNS, Ken. The Dust Bowl: An illustrated history. San Francisco: Chronicle Books, 2012.

FRENCH, Warren. John Steinbeck. Tradução de Elizabeth e Djalmir Mello. Rio de Janeiro: Lidador, 1966.

GALBRAITH, John Kenneth. O colapso da bolsa, 1929. Tradução de Carlos Nayfeld. São Paulo: Expressão e Cultura, 1972.

GATES, Paul Wallace. Land policy and tenancy in the Prairie States. The Journal of Economic History, Cambridge, n. 1, pp. 60-82, 1941.

GREGORY, James N. Dust Bowl legacies - The Okie impact on California, 1939-1989. California History, vol. 68, n. 3, Fall/1989, pp. 74-85. Disponível em: http://faculty.washington.edu/gregoryj/legacies.pdf. Acesso em: 24 mar. 2020.

KEYSERLING, Leon; NATHAN, Robert R.; CURRIE, Lauchlin B. Discussion - The Keynesian Revolution. The American Economic Review, Pittsburgh, vol. 62, n. 1-2, pp. 134-141, (March, 1972).

LANGE, Dorothea; TAYLOR, Paul Schuster. An American exodus: A record of human erosion. New Haven: Yale University Press, 1969.

MARSH, Fred T. In dubious battle and other works of fiction. The New York Times, 2 de fevereiro de 1936. Disponível em: https://timesmachine.nytimes.com/timesmachine/1936/02/02/85230823.html. Acesso em: 11 jul. 2018.

MITGANG, Herbert. Policing America's writers. New Yorker, October 5, 1987. Disponível em: https://www.newyorker.com/magazine/1987/10/05/policingamericas-writers. Acesso em: 19 mar. 2020

PARINI, Jay. Every time a friend succeeds something inside of me dies: The life of Gore Vidal. New York: Little Brown, 2015.

John Steinbeck, uma biografia. Tradução de Alda Porto e Marcos Santarrita. Rio de Janeiro: Record, 1998. 
ROEDIGER, David R. The wages of whiteness - The making of American working class. Revised edition. New York: Verso Books, 2007.

"State archives releases 'California Witch Hunt' - A new 3-part digital exhibit focuses on the CA Un-American Activities Committee. April 17, 2019. Disponível em: https://www.sos.ca.gov/administration/ news-releases-andadvisories/2019-news-releases-and-advisories/california-state-archives-witchhunt-new-3-part-digital-exhibit-unamerican-activities-committee/. Acesso em: 19 mar. 2020.

STATE OF CALIFORNIA. Senate Bill No. 670 by Senator Joseph Lawrence Dunn - Apology Act for the 1930s Mexican Repatriation Program. Oct 7, 2005. Disponível em: https:// leginfo.legislature.ca.gov/faces/billTextClient.xhtml?bill_id=200520060SB670. Acesso em: 24 mar. 2020.

STEINBECK, John. Ao deus desconhecido. $4^{\mathrm{a}}$ ed. Tradução de Nair Bisony Mazza. São Paulo: Ibrasa, 1981.

As vinhas da ira. Tradução de Ernesto Vinhaes e Herbert Caro. São Paulo. Abril Cultural, 1972.

Luta incerta. $2^{\mathrm{a}}$ ed. Tradução de A.B. Pinheiro de Lemos. Rio de Janeiro:Record, s.d.2

Record, s.d.1

$O$ vale sem fim. Tradução de A.B. Pinheiro de Lemos. Rio de Janeiro:

The harvest gypsies: On the road to The grapes of wrath. Berkeley: Heyday Books, 1988.

The long valley. Introduction and notes by John H. Timmerman. New York: Penguin Books, 1995.

STEINBECK, John; DeMOTT, Robert (ed.). Working days - The journals of The grapes of wrath. New York: Penguin Books, 1990.

STEINBECK, John; FENSCH, Thomas (ed.). Conversations with John Steinbeck. Jackson: University Press of Mississippi, 1999.

WHITT, Jan. "To do some good and no harm": The literary journalism of John Steinbeck. Steinbeck Review, Pennsylvania, vol. 3, issue 2, pp. 41-62, Fall/2006.

WILSON, Edmund. Classics and commercials - A literary chronicle of the Forties. New York: Farrar, Straus and Company, 1951. 
Recebido em: 14 de maio de 2020

Aceito em: 7 de agosto de 2020 